\title{
Graffiti: A form of international communication ${ }^{1}$
}

\author{
Sandra Žuvela ${ }^{2}$
}

Faculty of Political Science, University of Belgrade, Belgrade, Serbia

\section{UDC 316.723(1-21) : $316.774: 7.021 .346$}

\begin{abstract}
Summary: The purpose of this article is to discuss how graffiti has evolved from its primitive, prehistoric forms into an art form that evokes upheaval and yet expresses opinions that are insufficiently addressed by those in power and society in general. The subjects of this analysis will be different case studies from Latin America, United States, Singapore, South Africa and Serbia as examples of global problems and trends. Case studies and examples of prehistoric times will also serve as sources that will aid in identifying how graffiti has developed into a multinational form of communication.

This analysis deals with graffiti as an expression of political and social discontent, as a form of general rebellion and vandalism as well as the paradoxical appreciation that is promoted by the Graffiti Hurts Organization. This specific form of expressive art connects the 'underdogs' of society to mainstream society through a constant battle to be heard, seen and to raise awareness of dissatisfaction. Those who instigate vandalism and reaction from the public through executing this form of art also instigate a constant battle of erasure of symbols, colourful signs and creative drawings thus proving society's neglect.
\end{abstract}

Key words: graffiti, rebellion, vandalism, tagging, Graffiti Hurts Organization

\section{Introduction}

Graffiti is one of the most controversial forms of expression and communication in urban culture. There is a fine line between graffiti being a form of art and a form of vandalism. Whether it is art or vandalism graffiti belongs to, it

\footnotetext{
1 This paper was written as result of research in the field of all elements that contribute to the International Communications course as part of the Academic Master Studies at the Faculty of Political Sciences in Belgrade, Serbia.

2 Contact with author: alevuz@hotmail.com.
} 
still defines struggle, feeling and the desire for the anonymous to be heard. In order to understand the motives behind this urban phenomenon, it is important to get back to its roots through an analysis of the very beginnings of this art form and to examine how humans have always had the desire to communicate their perspectives on life. Through an analysis of its history, dating back to the prehistoric times right up until today, and different phases that graffiti went through as an art form and form of communication, it will become clear how its development has had an impact on human artistic and emotional expression. The analysis will also closely examine its placement in art, vandalism and protest in different countries such as Guatemala, Paraguay, Brazil, United States of America, Serbia, South Africa and China. The in-depth study will clarify and confirm that graffiti is in fact a global phenomenon of rebellion.

A brief introduction to the evolution of graffiti is necessary because the cave drawings at cave sites around the world are not graffiti as we know it today, but they portray symbols and pictures that represent primitive events and subject matter that was of concern then. Firstly, if we consider that caves such as those that are home to the very first graffiti found in Ancient Greece around 30,000 $\mathrm{BC}$, were prehistoric spaces of gathering, we immediately associate it with a social space of meeting and interaction. Messages that were inscribed onto walls show an early form of tagging. Tagging, according to the Webster online dictionary is, "an inscription, slogan, drawing, etc, scratched, scribbled, or drawn, often crudely, on a wall or other public surface". This means that early cave art is related to some of the symbolic and perhaps even random graffito one sees on facades of buildings today. However, a symbol or message that may seem random and meaningless to one, is differently interpreted by another and depends entirely on the context and time period in which it is executed.

\section{The prehistoric era and the beginnings of graffiti}

In prehistoric times, like modern graffiti, the drawings were done in colour but only using natural dyes as opposed to spray paint. The purpose of these cave drawings was born from the need to communicate with outside life, since the subject matter often focused on animals, religious processions, dances and customs. 


\section{Earliest forms of graffiti}

\section{Cave etchings}

Historian Russell Dale Guthrie conducted an interesting comparison between cave drawings found in Pleistocene caves in Southern parts of Europe (Guthrie, 2005: 44). He discovered that the subject matter of the prehistoric drawings were hunting and sexual acts. Another example we can use is that of the cave drawings found in the mountainous region of Drakensberg, South Africa and the very first cave drawings found in the region of France (Lascaux). They represent different religious ceremonies, dances and animals (Unesco, 2012). As every time period within human evolution is focused around a group of issues relevant to specific types of communities of the time, whether it is Africa or Europe, cave art resembles similar subject matter.

\section{Advancement of intellect}

According to Timothy and Daniel Gross, graffiti went through different stages to acquire the characteristics it is recognized by today (Gross \& Gross, 1993). In their article Changing Visual Patterns and the Rhetorical Implications of a New Form of Graffiti, they go on to explain that the history of graffiti can be compressed into four main phases. They describe the imitative phase as simply the phase where humans drew what they saw. Simple drawings were representations of life and thus a representation of a human's primitive state of mind. They see the transition phase as a step forward in human intellect where symbols in the form of fonts were introduced and combined with drawings. It seems that after these two phases graffiti began to evolve into a more serious form of expression. The Grosses use an interesting example in which they explain how an early form of graffito in the $3^{\text {rd }}$ century AD in Rome had a portrayal of a man worshipping a donkey, accompanied by the words, Alexamenos, worships God (Gross \& Gross, 1993). This particular graffito was found in the guardrooms of the Imperial Palace which means that it was done by ordinary people who had the desire to oppose what had been forced onto them. Through this example, Timothy and Daniel Gross conclude that it may be a mock of Christianity and a representation of an ongoing struggle at the time. It is clear that through the subject matter of the graffito, the people of that time began to possess a more intellectual means for expressing resistance. 


\section{Advancement of human thought and reason}

\section{A combination of thought and visual art}

Timothy and Daniel Gross also describe that graffiti in its very early forms went through another improvement (Gross \& Gross, 1993). According to them, it went through a phase of personal expression. This perhaps indicates that graffiti was beginning to fit into the criteria of the main purpose it served thousands of years ago and today: expression of thought. Whether its purpose is art or rebellion, either way graffiti is a form of communication. It is clear that graffiti evolved from a mere representation into a symbol or picture with actual purpose and deeper meaning. Graffiti (as a form of expression) began to advance and moved through the word message expression. It is important to note that graffiti 'doers', if we can call them such, began to graffiti only significant words or phrases.

The short phrases that were used were written in unclear fonts and often reflected the level of intellect of the people who executed them. There is an example of early graffiti that displayed the old Safaitic (Arabian dialect) language in which the ancient people used to communicate. Perhaps it is the only evidence there is of its existence in the first century B.C. In the final phase, Timothy and Daniel Gross take us through what is perhaps the most significant as the root of all graffiti today - the apocryphal phase (Gross \& Gross, 1993: 255). This is the period in which messages were disguised in words. These early words were a visual art form that contained hidden messages. This phase is very important because it reminds us that graffiti has always had three main criteria to fulfill: purpose, location and time. Early history of graffiti merely presents a base of knowledge for this form of communication that, although done in many cases anonymously, addresses entire crowds, groups or even nations.

\section{Role of tagging in political upheaval and social discontent}

The streets of downtown New York were symbolic of the struggle of African American people and were the birthplace of a whole new generation who strongly engaged in the fight for freedom through song and art, with graffiti being the most prominent throughout streets and the New York subway the 1960 's. We need to understand terms used to define graffiti in its entirety time, purpose and place. When looking at the term tagging, we associate it with personal referencing or rather a signature. The majority of the graffiti, especially those that were done in the struggles of 1920's where graffiti was done on 
boxcars all over the world, did in fact have a purpose and did reference certain events, people and places. Tagging is primarily an evocation and desire for attention, either gang related or directed at the public. It is the main aspect of this particularly complex form of communication when looked at from the angle of expressing violent rage.

\section{Expression of fury}

\section{Paraguay}

Blake Gopnik's article examines the graffiti of the 1980's and its roots in prehistoric times (Gopnik, 2011: 92-93). He claims that graffiti back then presented issues that were unspoken of and that today graffiti is predominately used to convey and communicate some form of message rather than an art form. In this case we can take a few countries as examples as well as use a case study to examine his theory. In 1986, Paraguay went through political upheaval due to major opposition parties and the struggle for freedom and human rights and critique of General Alfredo Stroessner's rule (with pressures from various groups of students and religious groups). If we examine the situation of Paraguay presented to us, we clearly see that censorship and corruption ruled for decades, where members of the very same government passed laws that were of Streossner's interests and, on the other side, an abundance of active groups of members of pro democracy political parties, the Catholic Church and students.

The capital city, Asuncion, can be used as an example of the country's hub of all activity: social and political (Chaffee, 1990: 127). From photographs presented in the latter, we see that the church was predominately responsible for the major change but we also see that the government propaganda was sprawled upon the walls within the city. People who opposed the government's system exercised graffiti to make a statement. This statement is juxtaposed with the series of events from the silent march in Paraguay in 1968 and 1986 where more than 40,000 people participated. The messages of the church looking out for the democratic needs of the people and their rights won the hearts of many and unified people and students. People who communicated the message of the Catholic Church were successful because their effort integrated people who opposed the system, caused a major concern and resulted in action.

Towns all over Paraguay were covered in street art (graffiti) as a protest against Stroessner's regime and in order to voice public opinion and awareness. It is clear that anti Stroessner groups had no other means of expressing utter dis- 
satisfaction other than protest and rebellion through graffiti. Using the theory of actions speaking louder than words, graffiti served as a form of communication between the opposition and the government. It is however interesting to see that in the city of Asuncion, student graffiti subject matter was not that of opposition or hatred. As Lyman Chaffee describes it, the graffiti that was seen at universities was romantic graffiti (Chaffee, 1990: 127). The message of love being automatically equal to peace was the primary concern of all students who in this particular case did not have violent rage in mind and their graffiti was not used as a form of violent protest but rather as a means of expressing personal feelings.

Vast amounts of graffiti targeting media and freedom of speech were found within the university buildings. The fact that a Law University was involved in the opposition to the government and Stroessner's rule was clearly the result of the formation of massive amounts of striking text such as, for a free university...for a people's university. At an Architecture University, striking text such as united we will defeat the repression was seen during the protests, inviting masses of crowds to join. One can gather that although the text does not require direct communication it causes a direct answer in forms of large groups of supporters.

Acronyms were enough to cause a sense of belonging for those that were pro-freedom and revolution. In Paraguay's case, PLRA (Authentic Liberal Radical Party), CEP (the Bishop's Conference Press), MURA (Renewed University Movement of Architecture), M-24 (24 of April Movement), MI (Inter-Union Movement of Workers) and MEUC (the Catholic University Student Movement) were all acronyms graffitied throughout the city that stood for various parties, and that were anti Stroessner and pro liberation. Through their supporters who spread messages throughout the cities' landscapes, these parties were able to gain support from those who empathized.

\section{Guatemala}

One can also look at the case of Guatemala. After thousands of people had been killed, the creation of Guatemala: Nunca Mas (Guatemala: Never Again) began and the series of community based graffiti, as Dr. Catherine Nolin puts it, has been aimed at remembering the government violence on the people of Guatemala (Nolin, 2006). Citizens made use of walls and other public spaces to draw pictures, post names and other significant phrases. The manner in which graffiti acts as a form of rebellion and resistance is twofold. If people have no other means of communicating their discontent, this inexpensive means of communication is what they thrive on. How can graffiti then be considered a 
rebellious act if it is used for the purpose of fighting for justice? In Dr. Nolin's article, there is an example of graffiti that says, Basta de violencia. This means enough to violence and is one of the many graffiti that represent anti violence in this period in Guatemala. How can one justify the removal of a peaceful proposition? Perhaps it is because there is always an urge to remove anything that does not fit in.

Nolin states in her analysis, "It is an extremely easy means of communicating ideas and establishing a collective identity with the masses by putting a government on notice that anti-system sentiments exist with a definite historical memory" (2006). A very good example of graffiti being used as a form of rebellion, and perhaps even bitter memory, is the case of Guatemalan conflict that had finally ended, yet still echoed throughout the towns with graffiti covering city facades. Dr Catherine Nolin's analysis focuses on the effects of political upheaval on the citizens in Guatemala and the most prominent way they have expressed themselves in-graffiti. It is obvious that citizens have used graffiti for communicating the effects of the past and their memory of loved ones and thousands of others who passed away.

Mara Salvatrucha (M-13) is the leading gang in Guatemala and their form of communicating amongst themselves and instigating threat to the public is through graffiti and tagging. The cryptic writing found on street corners and other buildings around Guatemala are described as rebellious tags because they are a mark of threat and spite to the public. Using a popular example as a representation of gangs all around the world with their gang initials or full names scribbled across public surfaces (as territorial marks), we are able to gain useful information about how they became infamous. Popular gangs are known for their horrible crimes and not only do they achieve fear from executing immense power over city streets, they feared by most other gangs. Their tagging marks the area they rule and thus instigates threat to citizens and a note of precaution to rival gangs.

The graffiti that consumes Guatemalan towns and its landscapes address political, economic, land and imperialism issues, as in phrases such as, a middleclass man that, without grace, mocks the town. We see from the study that most of the graffiti portrays Anti US messages and images of the United Sates taking over. Other graffiti that was found contain the following texts: No tolermas paises que contryan armos de destruction masiva (We do not tolerate countries that produce weapons of mass destruction), El intervnoinista es el terrorista (the interventionist is terrorist), a Frente Anarquista Estudiantil (the Student Anarchist 
Front) and El Partido Libertador Progresista (the Progressive Liberator Party). All these phrases and names of parties were sprayed on the walls in front of the American Embassy. The various parties, along with their supporters, graffitied their opinion and the parties' emblems to voice their support and admiration.

\section{Serbia}

Whether it is political or social, the subject matter and the purpose of graffiti is always the same: to communicate issues that are perhaps swept under the rug. In the capital city of Serbia, graffiti still thrives. Belgrade's freshly painted walls seem to be magnets for vandals who feel the need to make a mark. The fist, a line drawn through $E U$ letters, and 1389 (the year in which the battle of Kosovo took place) are the most common graffiti one can find (Eaton, 2012). The fight for freedom, the fight against entering the European Union, and revoking an event that still today echoes throughout the whole country, are all shown through simple graffito that citizens are all too familiar with.

If we use the graffito of the anti European Union, we are able to analyze it in many different ways. Whilst it seems like simple graffiti, it is a resemblance of a long hard battle over what divides the country. The graffito itself stirs up emotion. To a citizen who is neutral, it seems like degradation to the surroundings, and one is simply disgusted by the simple aesthetics of it ruining a façade, whilst those that are either anti or pro are overcomed not only by the appearance but also by the whole subtext it portrays. Some blocks of Belgrade are also marked by tagging and numbers to notify what gangs prowl the area or simply inhabitants of the particular block who take pride in where they live.

The case of Uroš Mišić is another very appropriate example to use when examining graffiti as a form of communication or anonymous messages to the public. This is the case of a young man who injured a police officer at a football game and was sentenced to prison, after which a group of his companions began to graffiti stenciled images of him accompanied by the slogan Pravda za Uroša or Justice for Uroš (Wallstalking Gallery, 2009).

The graffito of Uroš spread throughout the Balkans in the hopes of gaining sympathy for a crime. As previously mentioned, words and texts of graffiti may evoke anger or sympathy and, in this case, people who did not know that story may have had sympathy and expressed it with support in the effort to reduce the sentence. This particular example has been used to explain communication through the graffito and it is evident that the person who began this campaign must have had a close relation to Uroš. They gathered a group that supported Uroš and opposed his arrest and would spread the appeal for justice to even 
more people, gaining a greater support for the young man who had been imprisoned. Whilst images spread around neighborhoods, the word of Uros gained either negative or positive publicity that instigated a divide between citizens who either supported or opposed his imprisonment. Once the media began covering it the images spread around and more people were able to find out about him and associate the image and the slogan with the situation. They had the choice whether to support or stand against it.

\section{Graffiti as a taboo art form}

Interestingly enough graffiti is appreciated to a certain extent in countries like South Africa, where it has set new grounds for modern and expressive street art forms. Numerous facades in Cape Town and Johannesburg have been 'decorated' by various artistic and colorful graffiti with important awareness messages concerning aids, use of drugs and anti smoking campaigns. However, could graffiti still be a form of 'taboo', because it seems as there is in fact no room for graffiti in the places where there is need for foreign investment and large scale business buildings. Although South Africa hosts a specific case, where Apartheid did not allow art education and proper art facilities for other races, facades of backstreets of informal settlements seemed to be of great use to aspiring young artists communicating their feelings on repression and racism by which the country was and still is strangled (Clark, 1992).

\section{South Africa}

Caille Millner from Newsweek, Pacific edition, did an interview with some graffiti artists in South Africa and found out that government officials do oppose tagging but not murals as such (Millner, 2002: 54). Still, graffiti, regardless of the subject matter, has been controlled and is either encouraged greatly to be done on canvases and displayed at exhibitions, or still remains in underground tunnels and 'shady' areas of downtowns where crime and gang violence rule. "We simply want to regulate them, the way you would regulate putting up a billboard", the Executive Councilor for Safety and Health Ian Neilson stated, who hired graffiti artist Sky 189 to paint a mural for his campaign. He admits that he was worried about the impact on the artists' livelihood. He also states, "We're just seeking to clean up the city, not to criminalize their profession". This statement really is the key to this discussion. Could Ian Neilson in fact be saying that graffiti should only be executed if commissioned for? This defies the 
purpose of this form of communication. Those that are in need of expressing their discontent invite others to join their struggle and raise awareness. In this case, however, it is judged by their skill to produce an artwork by order in the mere function of decoration.

A graffiti artist who had been arrested in Singapore for spray painting mailboxes was released and commissioned to paint a large canvas in front of guard observation. Yet again we are faced with unfair judgment because the purpose of graffiti is to spontaneously communicate what is of concern and not be steered away from important subject matter. As Kolesnikov-Jessop states:

"Once officials get involved, art can lose its edge, and so Singapore is going to have to be very careful with that. Your heart can be in the right place, but you may still make a lot of mistakes. Singapore may be starting to see that graffiti isn't always vandalism, but in the art world there is no greater crime than being boring" (Kolesnikov-Jessop, 2010: 64).

Although Tuck Yew, the Singaporean acting minister for information, communications, and the arts, says that they are always trying to move a step further and improve the arts and culture of the city. There is a dose of control over the arts especially in the strict systems like Singapore and conservative Chinese government.

\section{Most common subjects expressed and addressed through graffiti}

A case study that was done in the 1990's by Emma Otta, who collected a series of 'inscriptions' from walls in men's and women's bathrooms in Sao Paolo Brazil, reveals some interesting results that are in short the answer to all subject matter of graffiti in general, whether it is protest act or art or defacement. Otta found that the main subject matter was sexuality, AIDS, racism, politics and religion. Although there were other subject matters contained in her research, it is important to focus on these because they symbolize the fight of human existence. To support this, Otta states, "All events that occur around them much like hunting was part of the prehistoric peoples' lives and of course not forgetting sexuality as the key subject matter - that is the key of all human existence" (Otta, 1993: 589-590). In both cases people have made inscriptions in pubic places of gathering with the intention of communicating current issues that were and still are considered taboo or public secrets. 


\section{Hypocritical appreciation of a two faced art form}

The fight to remove graffiti can be considered as censorship on a global scale, or is it simply just a justifiable excuse to control the esthetic appeal of towns and cities? This is the crucial question that the USA based Graffiti Hurts Organization aims to answer. One needs to understand that ideological parameters are not only set on politics and implementation of a certain kind of lifestyle, it is also implemented through art and controlling artistic expression. It directly controls freedom of rights, freedom of expression and most of all freedom of speech. On one hand, if it allows artists to express themselves and yet confines them to certain spaces or canvases that are not graffiti, any further communication with public is lost (Moreau \& Alderman, 2011: 106-124). Terri Moreau and Derek Alderman examine the main idea of the Graffiti Hurts Organization. Powerful organizations within countries are primarily in charge of setting up certain criteria of norms, mainly consumerist and political in value. They do away with anything that is remotely 'alien' a particular form of order.

Moreau and Alderman state, "Landscape plays a major role in silencing some perspectives and giving voice to others" (2011: 106). It is in fact a large canvas of inexpensive communication. If we observe who usually does graffiti we can actually see that it is mainly people who are rejected from 'mainstream' society. According to Moreau and Alderman, these are usually the homeless, poor, nomadic and protestors. This form of vandalism art is their only means of interpersonal and global communication. Due to strict policies, almost all cities have on landscapes they lean towards eradicating any graffiti. It is thus crucial to understand the purpose and effects Graffiti Hurts has on society and communication of opinion.

Whether it is art of vandalism, discrepancy about this form of anonymous communication always exists, and the need for its removal is just as prominent as the desire to spray. However, does this means that removing graffiti also means muffling opinion and even a form of censorship? The desire to remove graffiti is either because of its unaesthetic appeal to those who do not understand or simply do not care, and view it as a change to the appearance of any facade or landscape, or because voicing an opinion within a desired space attracts too much attention and evokes thought. Defining graffiti as a form of international communication and it being destructive is somewhat closely related. Since graffiti is an 'underground' activity, it can be said that it is a form of underground communication between the dissatisfied and the public. People incoherently 
judge it by the change it brings to the aesthetics of a landscape on which it is posted. To support this idea, Moreau and Alderman state:

"Generally speaking, they have a negative stigma and usually are associated with crime and gangs. As such, the reasons behind their appearance and the possibilities of what an inscription may signify are frequently ignored, especially by those who are in charge with cleaning up" (Moreau \& Alderman, 2011: 110).

\section{An attempt at appreciation}

\section{The Graffiti Hurts Organisation}

Could the generally biased opinion about graffiti change? The Graffiti Hurts Organization sub-textually does not support graffiti; it detours graffiti artists to doing murals that serve as a replacement for city walls and facades. The face value of graffiti is depreciated. Can doing a mural be a product of the same person who is free to graffiti in the spur of the moment when filled with an abundance of emotion? Similar to the case in Sydney, Graffiti Hurts supports graffiti in the sense of it being done within a confined space. It clearly displays the attitude that graffiti can only be appreciated as art if it is done on a canvas or a designated area; otherwise, it has to be prevented. Once again, it is clear that The Graffiti Hurts Organization does not see graffiti as a form of communication but as mere form of defiant disfigurement to city landscapes. It uses a globally recognized form of communication - the internet - to educate people around the world about what graffiti is and its purpose as a form of communication.

Care, as Graffiti Hurts uses the word, refers to keeping business and property values intact and inactive and marginalized groups secured rather than listening to their needs. Moreau and Alderman's statement makes a lot of sense because eradicating graffiti is paired with eliminated art and opinion. Cave drawings are regarded today as sacred and rare. Prehistoric people like people of today used these primitive graphics as a means of communication within their tribes. Getting rid of cave paintings would simply mean getting rid of early art and history. 


\section{Conclusion}

Although the world does not speak the same language, it understands the same symbols and other visual objects drawn on facades. Flags and symbols such as the Swastika are always going to be associated with Hitler and the Holocaust, and in many countries the American flag will be associated with American imperialism and superiority. It is clear that the Graffiti Hurts Organization does not recognize the artistic or communicative qualities of graffiti, but instead focuses on the vandalistic and destructive reputation it has acquired due to the aspects that connect it to problems of society. In conclusion, it is clear that graffiti as a form of international and multicultural communication has evolved from being a representation of primitive acts in prehistoric times to displaying cryptic messages and famous places that evoke admiration or protest throughout countries worldwide. Either way, graffiti has successfully placed itself as a notorious means of communicating discontent, spite, territorial marking and has successfully divided the world in half: those who appreciate it and those who hate it.

\section{References}

Guthrie, R.D. (2005). The Nature of Paleolithic Art. Chicago: The University of Chicago Press.

United Nations Educational, Scientific and Cultural Organisation (19922012). uKhahlamba Drakensberg Park. Accessed : 29.06.2012. URL: http:// whc.unesco.org/en/list/985/.

Chaffee, L. (1990). The popular culture political persuasion in Paraguay: Communication and public art. Studies in Latin American Pop Culture, 9, 127-149.

Eaton, G. (2012). Belgrade - beyond the trenches. New Statesman. Accessed: 28.06.2012. URL: http://www.newstatesman.com/travel/2012/01/serbiabelgrade-life-national?quicktabs_most_read=0.

Clark, E. (1992). South African History Online: Protest Art In South Africa 1968-1976: A Study of its Production, Context and Reception. Accessed: 
29.06.2012. URL: http://www.sahistory.org.za/archive/protest-art-southafrica-1968-1976-study-its-production-context-and-reception

Gross, D., \& Gross, T.D. (1993). Tagging: Changing visual patterns and the rhetorical implications of a new form of graffiti. Et Cetera - A Review of General Semantics, 50, 251-264.

Gopnik, B. (2011). Revolution in a can. Foreign Policy, 189, 92-93.

Hanratty, M., \& Meditz, S. (1988). Paraguay: A country study. Washington: GPO for the Library of Congress. Accessed : 05.01.2012. URL : http:// countrystudies.us/paraguay/2.htm.

Khammash, A. (2002). Pella Museum: Safaitic art. Accessed: 05.01.2012. URL: http://www.pellamuseum.org/Pella_Museum/Geology_Tourism/ Safaitic_Art.htm

Kolesnikov-Jessop, S. (2010). The Writing on the Wall, Newsweek, 12 (133), 64.

Millner, C. (2011). Kings of Spray. Newsweek, 17(139), 544.

Moreau, T., \& Alderman, D.H. (2011). Graffiti Hurts and the eradication of alternate landscape. Geographical Review, 1(101), 106-124.

Nolin, C. (2006). Memory and resistance: Graffiti in postconflict Guatemala: Disappearance. Accessed: 05.01.2012. URL: http://guategraffiti.webs.com/ disappearancedisplacement.htm.

Nolin, C. (2006) . Memory and resistance: Graffiti in postconflict Guatemala: Economics. Accessed: 05.01.2012. URL : http://guategraffiti.webs.com/ economics.htm .

Otta . E. (1993). Graffiti in the 1990s: A study of inscriptions on restroom walls. Journal of Social Psychology, 4(133), 589-590 .

Rassias, V. (2000). Pagan destruction chronology. Accessed: 20.01.2012. URL: http://www.bibliotecapleyades.net/biblianazar/esp_biblianazar_33.htm.

Tagging. (2012). In Webster Online Dictionary. Accessed: 02.01.2012. URL : http://www.merriam-webster.com/dictionary/tagging.

Zimu, M. (2012). New rules for Berg Rock Art Visits. Accessed : 21.01.2012. URL: http://www.iol.co.za/dailynews/news/new-rules-for-berg-rock-artvisits-1.1160915. 